\title{
Analysis and comment
}

\section{Controversy}

\section{NHS maternity units should not encourage commercial banking of umbilical cord blood}

\section{Leroy C Edozien}

Storing cord blood at birth as insurance against future disease may sound like a good idea to parents, but it has worrying implications for NHS services and little chance of benefit

Increasing numbers of women in maternity units across the United Kingdom are requesting collection of umbilical cord blood at delivery to enable storage of stem cells for possible autologous transfusion in the future. Such commercial banking of cord blood has important implications for National Health Service maternity units. The debate on whether commercial cord blood banking should be encouraged has mostly been limited to the scientific merits, but risk management, medicolegal, and ethical issues also need considering.

\section{Growth of blood banking}

Umbilical cord blood is rich in stem cells that can be used to treat patients with abnormal haematopoietic cell lines, childhood leukaemia, or metabolic diseases. ${ }^{1}$ Bone marrow is used for this purpose, but cord blood is cheaper and easier to obtain and less likely to trigger a harmful immune response or rejection in the recipient. ${ }^{2}$

For these reasons interest has been growing in banking cord blood. The collected sample is commercially processed and stored for possible autologous transfusion in the future, a practice commonly referred to as biological insurance.

Media hype about the potential of stem cell transplantation ${ }^{3}$ and marketing by the commercial cord blood banks are likely to increase requests for blood collection at delivery. These banks advertise on the internet, distribute literature in antenatal clinics, and directly approach doctors and midwives.

A booklet distributed by one of the commercial banks tells potential clients that, "The cure for many life threatening diseases is dependent on the transplantation of stem cells." It speaks of "unimaginable possibilities" and states: "Potentially [stem cell] research should provide answers to curing diseases such as diabetes, breast cancer, ovarian or testicular cancer, melanoma, rheumatoid arthritis, Parkinson's as well as regeneration of damaged heart tissue."

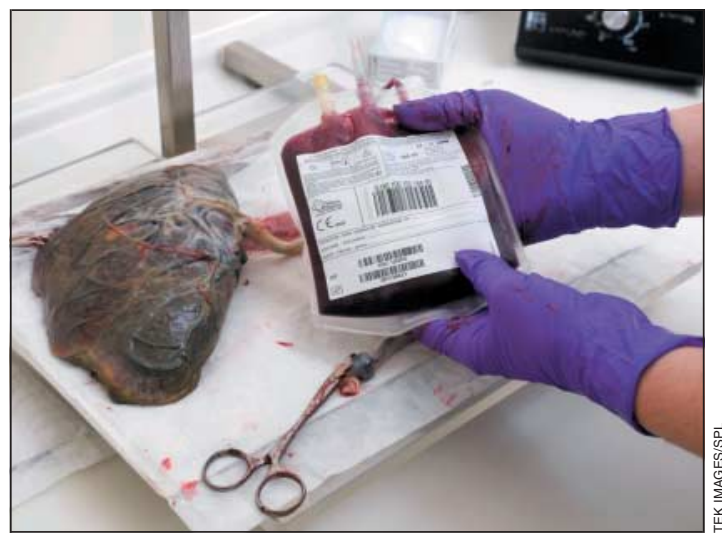

St Mary's Hospital, Manchester M13 0JH Leroy C Edozien consultant obstetrician and gynaecologist Leroy.Edozien@ cmmc.nhs.uk

\section{Public and commercial banking}

The NHS has been banking donated cord blood since 1996 through designated public banks operated by the National Blood Service. Public banks collect cord blood that has been altruistically donated for haemopoietic stem cell transplantation, similar to bone marrow donation. These banks use established links with maternity units to collect cord blood on a regular basis through standard procedures and by appropriately trained staff working separately from those providing routine peripartum care.

Altruistic cord blood donations are used to treat unrelated recipients (allogeneic transplantation). Public banks also operate directed banking of cord blood in families affected by or known to be at risk of diseases that are treatable by transplanting blood stem cells. Cord blood is collected from siblings born into such families.

By contrast, commercial banks operate collection and storage of a baby's cord blood for later use by that person (autologous transplantation) or their siblings. Blood is collected just in case the baby later develops an illness such as leukaemia, which could be treated by transplantation of cord blood stem cells.

Commercial banking has been criticised by numerous medical bodies, including the Royal College of Midwives, ${ }^{5}$ Royal College of Obstetricians and 
Gynaecologists, ${ }^{6}$ American Academy of Pediatrics, ${ }^{7}$ Society of Obstetricians and Gynaecologists of Canada, ${ }^{8}$ American College of Obstetricians and Gynecologists, ${ }^{9}$ French National Consultative Ethics Committee for Health and Life Sciences ${ }^{10}$ and the European Group on Ethics in Science and New Technologies. ${ }^{11}$ In a recently revised position paper, the Royal College of Obstetricians and Gynaecologists reaffirmed that routine directed commercial cord blood collection and stem cell storage cannot be recommended because of the insufficient scientific base and the logistic problems of collection for NHS providers. ${ }^{6}$

\section{Scientific argument}

The advantages of commercial cord blood banking are that the child has blood stored for possible use in the future and would be able to benefit from advances in technology. The question is whether these advantages are real or hypothetical. Some scientists have tried to make a case for commercial banking based on the scientific possibilities of stem cell therapy, ${ }^{12}$ but most of the acclaimed benefits apply to allogeneic transplantation and not necessarily to autologous transplantation.

The scientific argument against commercial cord blood banking can be summarised as follows ${ }^{6-15}$ :

- The likelihood that the stored blood will be used is very low (estimates range from 1 in 1400 to 1 in $20000^{11}{ }^{13}$ )

- Advances in conventional treatment and allogeneic transplantation mean only a few patients with acute leukaemia will require autologous transplantation. If autologous stem cells are required they could be harvested from bone marrow or peripheral blood

- Autologous cord blood may not be the best option-for example, pre-leukaemic mutations or leukaemic cells may be present in cord blood of children who later develop leukaemia ${ }^{15} 16$

- Alternatives to autologous cord blood are available for people who require transplantation. These include marrow from a living related donor or cells from a matched donor from a public cord blood bank

- Arguments by commercial cord blood banks that cord blood could be used to treat diabetes and other diseases are speculative.

\section{Risk management issues}

Whatever the scientific merits or demerits, commercial collection and banking of cord blood presents many other risks that need to be taken into account. Blood can be collected from the cord while the placenta is still in utero after vaginal delivery or caesarean section (in vivo collection) or after the placenta has been delivered (in vitro collection). ${ }^{17}{ }^{18}$ In vivo collection may yield larger volumes ${ }^{19}{ }^{20}$ but could interfere with the mother's care-and who is to decide whether the collection takes precedence over some aspect of care: the mother or the midwife? In vitro collection increases the risk of the specimen being contaminated with bacteria or maternal fluid.

Time spent on collecting cord blood is time away from the care of this mother, the baby, and, critically, other patients, which raises ethical questions about equitable treatment of patients. Collection of cord blood could also interfere with cord blood gas analysis. Cord blood gas analysis is important in diagnosing fetal acidosis and has both clinical and medicolegal implications. What happens when samples have to be collected for both gas analysis and commercial storage? It is easy to say that the former takes priority; in practice, some parents may want it the other way.

If NHS units are to encourage commercial cord blood banking, time has to be set aside for obtaining valid consent. The consent procedure, blood collection, labelling, and associated paperwork all place an extra burden on staff. When English is not the woman's first language, a link worker will be required to obtain valid consent.

Multiple pregnancy and preterm labour create further problems. Multiple pregnancies increase the scope for error in labelling the cord blood units and for cross contamination-with serious implications for non-identical twins. Cord blood collected at preterm deliveries may contain lower nucleated cell counts. ${ }^{21}$ Delayed (rather than early) cord clamping is associated with less need for transfusion and less intraventricular haemorrhage in preterm babies ${ }^{22}$ but will compromise cord blood yield. These risks have to be discussed in advance with the woman.

Maternity units have an ethical if not legal obligation to minimise the risk of infection in cord blood units. Chorioamnionitis, genital herpes, and tears of the placental vessels due to traction all predispose to contamination, and units will have to put systems in place to pick up these risks and contain them. Ideally, the unit collecting umbilical cord blood should screen the mother for infection, including a history of overseas travel, exposure to live viral vaccines, and use of recreational drugs. These processes have resource implications that extend beyond mere collection of a sample of blood at delivery.

Concerns about quality relate not only to collection of the blood sample but also to the processing and storage of cord blood units. The European tissues and cells directive that came into force on 7 April 2006 applies to stem cells. Cord blood banks must comply with specified standards for the procurement, processing, and storage of these cells. If a maternity unit participates in the collection of cord blood it would need to meet the specified standards. Public banks have stringent quality standards, particularly in relation to infection, but in the United States private banks are reported to have lobbied hard against regulation..$^{18}$

These logistical problems do not apply to altruistic donation because the blood is collected by specially trained staff who are not involved in routine care and there is no imperative to obtain a sample from any particular woman. Care has to be taken to obtain valid consent, but the number of collections is contained by the available resources.

\section{Medicolegal issues}

Apart from consent, there are other medicolegal factors to consider. Questions arise regarding indemnity if a sample is inadequate, contaminated, or mislabelled or in any other way unsuitable for use. Are the hospital, individual practitioners, and defence organisations exempt from liability? Does collection of cord blood for commercial banking count as part of routine 
NHS care? If it does, is the NHS obliged to train all staff in collection, and will the cost of such training be ethically justifiable given competing claims on limited resources and cost-benefit considerations?

In addition to indemnity, issues relating to property rights ${ }^{23}$ over the cord blood must be considered by units collecting cord blood. The sample may be deemed to belong to the mother today (the contract is between the mother and the cord blood bank) but could the child be suing the bank or the mother for property rights to the cord blood in the future?

Legal battles are also occurring over patents. A US company is reported to have sent a letter in June 2004 warning obstetricians that collection of blood for a competitor was an infringement of patent. ${ }^{18}$ Although the battle has not shifted to UK courts, units wishing to collect cord blood for commercial banking must seek legal advice.

\section{Ethical considerations}

Some people would argue that the medical establishment's discouragement of "just in case" collection of cord blood is an extension of medical paternalism. If parents want it and can pay for it, our duty should be to provide all the information we can. The decision whether to store cord blood should be taken by parents not by the healthcare providers. On the other hand, parents anxious to do the best they can for the unborn child are in a vulnerable position, and their autonomy is readily compromised by suggestive mailing, promotion, or advertising. Considering the stringent standards applied by ethics committees in relation to recruitment of pregnant women into research studies, it is paradoxical that when it comes to commercial cord blood banking NHS facilities could be used to promote a service that has no proved benefits.

As I have already pointed out, there are other ethical reasons not to encourage commercial cord blood banking. The idea of a midwife or doctor spending time on cord blood collection when other women need care, and in the face of a staffing (particularly midwifery) shortage, raises ethical questions. Given the logistical burden it imposes, routine on-demand collection of umbilical cord blood for commercial storage calls for dedicated resources. In the context of the NHS, such resources are better directed to meet broader and more pressing needs.

\section{Public policy perspective}

From the public policy perspective, it can be argued that constraining commercial cord blood banks will inhibit innovation in the science of cord blood stem cells and inhibit the growth of new biotechnology companies. This could have implications for scientific research and development and for the national economy in the long term.

The counterpoint is that promoting commercial cord blood banking would undermine the good work done by public banks. For equitable access to stem cells, altruistic donations should be encouraged. If cord blood samples are held for life in commercial banks, they are unavailable to other people who may need them. Donated samples can be traced, which means that if an altruistic donation is made and the donor

\section{Summary points}

Commercial banks are encouraging parents to store umbilical cord blood in case their child needs it in future

The chances of the blood being used are very small

Collection of cord blood raises serious resource, legal, and ethical issues for NHS maternity units

Commercial collection of cord blood should be discouraged

subsequently needs transplantation, autologous transplantation with the donated cells may still be possible.

Beyond the scientific and logistic issues there are other questions such as what happens to the cord blood if the commercial bank collapses.

\section{Conclusion}

The balance of argument is tilted strongly against NHS trusts collecting cord blood for commercial banking. No new scientific development warrants departure from the stated positions of various medical bodies. Even if the rapid pace of technological advancement results in today's speculation becoming tomorrow's reality, risk management, medicolegal, ethical, and public policy considerations militate against commercial collection of cord blood in NHS maternity units. It should therefore be NHS policy not to facilitate umbilical cord blood collection by its staff.

Women will continue to request such collection, and it is our responsibility to provide them with adequate information explaining why commercial banking is not encouraged. As well as being given a realistic assessment of the value of cord blood banking, parents need to know how their care, and the care of other women, can be affected by cord blood collection and what could go wrong during collection. Maternity units should produce patient information leaflets providing evidence based information on this subject, as recommended by the royal colleges. ${ }^{16}$

Contributors and sources: LE holds legal as well as medical qualifications and has a longstanding interest in healthcare risk management and medicolegal issues. This article arose from his assignment to produce a policy on commercial cord blood banking for his NHS hospital last year.

Competing interests: None declared.

Rogers I, Casper RF. Umbilical cord blood stem cells. Best Pract Res Clin Obstet Gynaecol 2004;18:893-908.

2 Rocha V, Wagner JrJE, Sobocinksi KA, Klein JP, Zhang MJ, Horowitz MM, et al. Graft-versus-host disease in children who have received a
cord-blood or bone marrow transplant from an HLA-identical sibling. $N$ Engl J Med 2000;342:1846-54.

3 Derbyshire D. Cord blood stem cells aid repair of hearts. Daily Telegraph Derbyshire D. Cord blood stem cells aid repair of hearts. Daily Telegraph
$2004 \mathrm{Feb} 17$. www.telegraph.co.uk/news/main.jhtml?xml =/news/2004/ 02/17/wcell17.xml\&sSheet $=/$ news/2004/02/17/ixworld.html (accessed 21 Aug 2006).

4 Cells Limited. Information booklet. Harrow: Cells Limited, 2005.

5 Royal College of Midwives. Guidance paper 1a: commercial umbilical cord blood collection. RCM Midwives 2002;5:422-3.

6 Royal College of Obstetricians and Gynaecologists. Umbilical cord blood banking. SAC opinion paper 2. London RCOG, 2006. www.rcog.org.uk/ index.asp?PageID $=545$ (accessed 21 Aug 2006).

7 American Academy of Pediatrics Work Group on Cord Blood Banking. Cord blood banking for potential future transplantation: subject review. Cord blood banking for po
Pediatrics 1999;104:116-8.

8 Armson BA, Maternal/Fetal Medicine Committee, Society of Obstetricians and Gynaecologists of Canada. Umbilical cord blood banking: 
implications for perinatal care providers. J Obstet Gynaecol Can 2005;27:263-90.

9 American College of Obstetricians and Gynecologists. ACOG committee opinion. Routine storage of umbilical cord blood for potential future transplantation. Int J Gynaecol Obstet 1997;58:257-9.

10 National Consultative Ethics Committee for Health and Life Sciences. Opinion number 74: umbilical cord blood banks for autologous use or for research. Paris: CCNE, 2002. www.ccne-ethique.fr/english/starthtm (accessed 21 Aug 2006)

11 European Group on Ethics in Science and New Technologies. Ethical aspects of umbilical cord blood banking. Strasbourg: European Commission, 2004. www.who.int/ethics/en/ETH_TissueBanking.pdf (accessed 21 Aug

12 Fisk NM, Roberts IAG, Markwald R, Mironov V. Can routine commercial cord blood banking be scientifically and ethically justified? PLoS Med 2005;2(2): 44 .

13 Johnson FL. Placental blood transplantation and autologous bankingcaveat emptor. J Pediatr Hematol Oncol 1997;19:183-6.

4 Ecker JL, Greene MF. The case against private umbilical cord blood banking. Obstet Gynecol 2005;6:1282-3.

15 Rowley J. Backtracking leukemia to birth. Nat Med 1998;4:150-1.

16 Gale KB, Ford AM, Repp R, Borkhardt A, Keller C, Eden OB, et al. Backtracking leukemia to birth: identification of clonotypic gene fusion sequences in neonatal blood spots. Proc Natl Acad Sci USA 1997;94:13950-4.

17 Warwick R, Armitage S. Cord blood banking. Best Pract Res Clin Obstet Gynaecol 2004;18:995-1011.

18 Moise KJ. Umbilical cord stem cells. Obstet Gynecol 2005;106:1393-407.

9 Pafumi C, Farina M, Bandiera S, Cavallaro A, Pernicone G, Russo A, et al. Differences in umbilical cord blood units collected during cesarean section, before or after the delivery of the placenta. Gynecol Obstet Invest 2002;54:73-7.

20 Solves P, Mirabet V, Larrea L, Moraga R, Planelles D, Saucedo E, et al. Comparison between two cord blood collection strategies. Acta Obstet Gynecol Scand 2003;82:439-42.

21 Nakagawa R, Watanabe T, Kawano Y, Kanai S, Suzuva H, Kaneko M, et al. Analysis of maternal and neonatal factors that influence the nucleated and CD34+ cell yield for cord blood banking. Transfusion 2004;44:262-7.

22 Rabe H, Reynolds G, Diaz-Rossello J. Early versus delayed umbilical cord clamping in preterm infants. Cochrane Database Syst Rev 2004;(4):CD003248.

23 Munzer SR, Smith FO. Limited property rights in umbilical cord blood for transplantation and research.J Pediatr Hematol Oncol 2001;23:203-7.

(Accepted 28 July 2006)

doi 10.1136/bmj.38950.628519.68

\section{Health research}

\section{How to formulate research recommendations}

P Brown, K Brunnhuber, K Chalkidou, I Chalmers, M Clarke, M Fenton, C Forbes, J Glanville, N J Hicks, J Moody, S Twaddle, H Timimi, P Young

"More research is needed" is a conclusion that fits most systematic reviews. But authors need to be more specific about what exactly is required

BMJ Publishing Group, London WC1H 9JR

Polly Brown

publishing manager

Klara Brunnhuber

clinical editor

National Institute

for Health and

Clinical Excellence,

London

WC1V 6NA

Kalipso Chalkidou

associate director,

research and

development

Database of

Uncertainties about

the Effects of

Treatments, James

Lind Alliance

Secretariat, James

Lind Initiative,

Oxford OX2 7LG

Iain Chalmers

director

Mark Fenton

editor

UK Cochrane

Centre, Oxford

OX2 7LG

Mike Clarke

director

continued over

BMJ 2006;333:804-6
Long awaited reports of new research, systematic reviews, and clinical guidelines are too often a disappointing anticlimax for those wishing to use them to direct future research. After many months or years of effort and intellectual energy put into these projects, authors miss the opportunity to identify unanswered questions and outstanding gaps in the evidence. Most reports contain only a less than helpful, general research recommendation. This means that the potential value of these recommendations is lost.

\section{Current recommendations}

In 2005, representatives of organisations commissioning and summarising research, including the BMJ Publishing Group, the Centre for Reviews and Dissemination, the National Coordinating Centre for Health Technology Assessment, the National Institute for Health and Clinical Excellence, the Scottish Intercollegiate Guidelines Network, and the UK Cochrane Centre, met as members of the development group for the Database of Uncertainties about the Effects of Treatments (see bmj.com for details on all participating organisations). Our aim was to discuss the state of research recommendations within our organisations and to develop guidelines for improving the presentation of proposals for further research. All organisations had found weaknesses in the way researchers and authors of systematic reviews and clinical guidelines stated the need for further research. As part of the project, a member of the Centre for Reviews and Dissemination undertook a rapid literature search to identify information on research recommendation models, which found some individual methods but no group initiatives to attempt to standardise recommendations.

\section{Suggested format for research recommendations on the effects of treatments}

\section{Core elements}

E Evidence (What is the current state of the evidence?) P Population (What is the population of interest?) I Intervention (What are the interventions of interest?) C Comparison (What are the comparisons of interest?) O Outcome (What are the outcomes of interest?) T Time stamp (Date of recommendation)

Optional elements

d Disease burden or relevance

$t$ Time aspect of core elements of EPICOT

s Appropriate study type according to local need

In January 2006, the National Coordinating Centre for Health Technology Assessment presented the findings of an initial comparative analysis of how different organisations currently structure their research recommendations. The National Institute for Health and Clinical Excellence and the National Coordinating Centre for Health Technology Assessment request authors to present recommendations in a four component format for formulating well built clinical questions around treatments: population, intervention, comparison, and outcomes (PICO). ${ }^{1}$ In addition, the research recommendation is dated and authors are asked to provide the current state of the evidence to support the proposal.

Details of participating organisations are on bmj.com 